\title{
Most people prefer constant carbon costs over increasing cost schedules even if costs are high
}

\begin{abstract}
We find that the public prefers the costs of climate action to be constant over time, irrespective of whether average costs are low or high. Policymakers interested in combating global warming should therefore introduce policies that initially rely on stable cost schedules instead of the widely discussed alternative of ramping up costs over time.
\end{abstract}

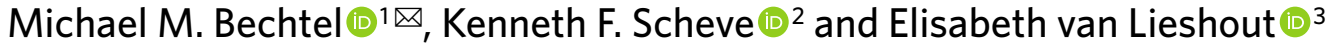 \\ BASED ON Bechtel, M. M., Scheve, K. F. and van Lieshout, E. Nat Clim. Change 10, 1004-1009 (2020).
}

\begin{abstract}
The policy problem
Devising effective responses to global warming requires policies that raise the price of carbon. However, as has been powerfully demonstrated by the Yellow Vests movement, costly climate action can provoke forceful public backlash. A widely held conjecture is that, among the possible cost schedules, that is, the ways in which costs can be distributed over time, policies that gradually increase the price of carbon will minimize public opposition to climate action as compared with constant costs. However, such claims lack empirical support. Knowing which cost schedule - increasing or constant - is more appealing to the general public is crucial for policymakers interested in designing carbon price policies, based on cap-and-trade or tax, that promise to be effective and politically sustainable.
\end{abstract}

\section{The findings}

We find that the public has a clear preference for constant carbon pricing schedules. Figure 1 a shows that $58 \%$ of all respondents favour a constant cost schedule over increasing, decreasing and inverse-U-shaped allocations. We also note that only $12 \%$ support an increasing cost path that would gradually ramp up costs over time. In addition, these preferences are surprisingly similar across countries (Fig. 1b). When we randomly provide half of the respondents with cost schedules that specify the average costs associated with a plan to be low and another half with a high cost version of our question, we still find that most people prefer constant cost schedules (Fig. 1c,d).

Additional results that rely on a climate policy conjoint experiment that randomizes both cost schedules and cost levels confirm this finding. Our study does not, however, rule out the possibility that low and stable cost plans may successfully introduce citizens to carbon pricing and build future support for higher carbon price plans in the long run.

\section{The study}

We devised a survey that we conducted among representative samples of the adult populations $(n=10,075)$ of four major

\section{Messages for policy}

- Credible climate policies will have to raise the price of carbon even if the public is averse to costs. Attractive policy design features can mitigate some of the concerns caused by increased carbon prices.

- In contrast to the common conjecture, the public prefers constant over increasing cost schedules even if average cost levels are high.

- Costly climate action will provoke less opposition if policymakers initially select plans that keep costs stable, as this allows individuals to smooth consumption over time.

developed economies (France, Germany, the United Kingdom and the United States). The survey included direct questions that were combined with experimental items. The evidence presented here relies on a direct question item which, for the European portion of our survey, was combined with an experiment that randomized whether the average monthly household costs associated with a potential climate agreement were low $(€ 28, € 39$ and $£ 15)$ or high $(€ 113, € 154$ and $£ 60)$ in France, Germany and the United Kingdom, respectively.

We then presented respondents with four different ways of distributing the costs of implementing an international climate agreement over time: constant, decreasing, increasing and inverse-U-shaped (in randomized order). We subsequently asked them to indicate which cost schedule they would select in a referendum given a certain average cost level.

Published online: 28 October 2021

https://doi.org/10.1038/s41558-021-01202-7 
a
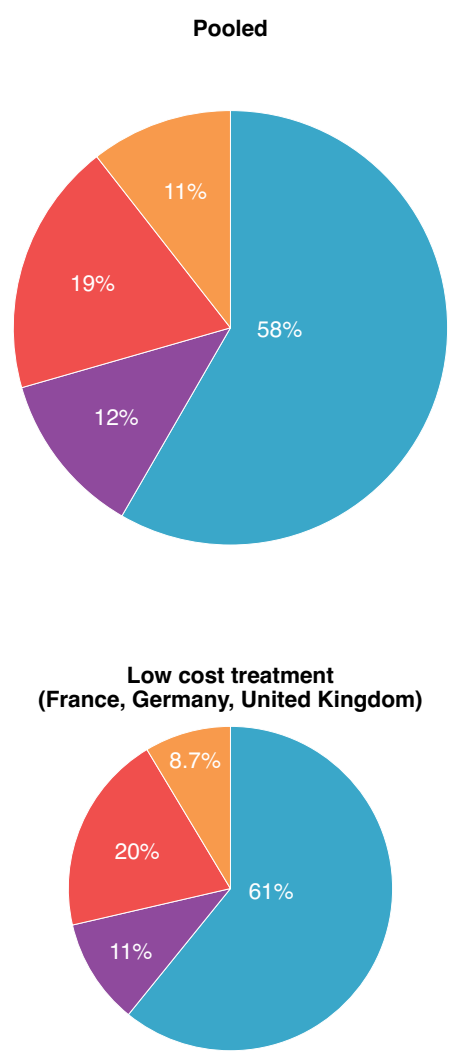

b

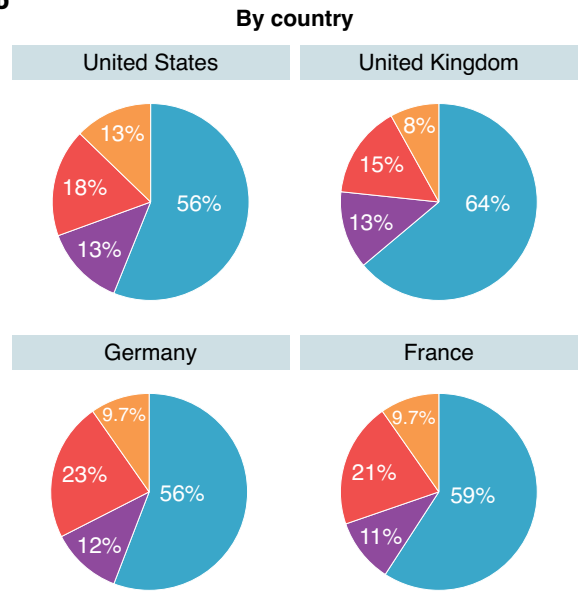

d

High cost treatment

(France, Germany, United Kingdom)

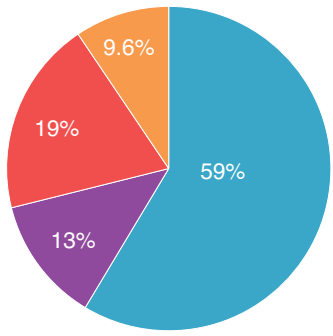

Constant Increasing Decreasing Inverse U

Fig. 1 Preferences for distributing climate costs over time. a,b, The percentage of respondents who prefer constant, increasing, decreasing or inverse-U-shaped intertemporal allocations of climate costs. Data are pooled (a) $(n=10,075)$ and shown by country (b) (France, $n=2,000 ;$ Germany, $n=2,000 ;$ United Kingdom, $n=2,000$; United States, $n=4,075$ ). c, Low average monthly household costs for implementing the agreement were set to $€ 28$, $€ 39$ and $€ 15$ for France, Germany and the United Kingdom, respectively. d. High average monthly household costs for implementing the agreement were set to $€ 113$, $€ 154$ and $€ 60$ for France, Germany and the United Kingdom, respectively.

\section{Further reading}

Nordhaus, W. Climate change: the ultimate challenge for economics. Am. Econ. Rev. 109, 1991-2014 (2019).

This article offers a review and discussion of the economic challenges arising from global warming, including the idea to gradually ramp up the costs of carbon over time.

Keohane, R. O. \& Victor, D. G. Cooperation and discord in global climate policy. Nat. Clim. Change 6, 570-575 (2016).

This study identifies political hurdles to international climate cooperation, highlighting the importance of costs and their distribution as drivers of national interests.

Obradovich, N., Tingley, D. \& Rahwan, I. Effects of environmental stressors on daily governance. Proc. Natl Acad. Sci. USA 115, 8710-8715 (2018).

This article empirically investigates the adverse effects of global warming on the ability of countries to perform essential functions for public goods provision, such as providing public health and safety.
Tingley, D. \& Tomz, M. Conditional cooperation and climate change. Comp. Political Stud. 47, 344-368 (2014).

This study provides survey evidence from multiple countries on whether the willingness of the public to back climate policy is conditional on other countries participating.

Bechtel, M. M. \& Scheve, K. F. Mass support for global climate agreements depends on institutional design. Proc. Natl Acad. Sci. USA 110, 13763-13768 (2013).

This article explores how design features of international agreements, such as costs, participation and enforcement, affect mass support for climate action.

\section{Acknowledgements}

M.M.B and K.F.S. gratefully acknowledge financial support from the Swiss Network for International Studies and the Weidenbaum Center on the Economy, Government, and Public Policy at Washington University in St. Louis. K.F.S thanks the Institute for Research in the Social Sciences for a faculty fellowship. We thank S. Weiss for valuable research assistance.

\section{Competing interests}

The authors declare no competing interests. 